\title{
La aparición de InfoLibre y eldiario.es para la defensa de un periodismo más democrático y participativo
}

\author{
Ana Virginia Rubio JoRDÁN \\ Universidad a Distancia de Madrid \\ anavirginia.rubio@udima.es
}

\begin{abstract}
Resumen:
InfoLibre y eldiario.es son dos medios de reciente aparición que, ante la crisis que vive el periodismo, han nacido únicamente en formato digital. Estos diarios se presentan como defensores de los principales ideales democráticos, la libertad de prensa y la defensa de los derechos humanos, entre otros. Su fórmula mixta de financiación les permite obtener ingresos de dos maneras: a través de las aportaciones que realizan sus socios y mediante la venta de espacios publicitarios. En esta comunicación se analizan las diferencias y similitudes presentes en ambos.
\end{abstract}

Palabras clave: prensa digital; periodismo participativo; democracia

\section{InfoLibre and eldiario.es, the appearance of two digital newspapers advo- cates of a more democratic and participatory journalism}

\begin{abstract}
:
InfoLibre and eldiario.es are two emerging media that due to the crisis in jourmalism, are born only in digital format. These diaries are presented as defenders of the major democratic ideals, freedom of the press and human rights, among other. Its formula mixed funding allows them to obtain income in two ways: through the contributions made by its members and by selling advertising space.
\end{abstract}

Key Words: Digital press; participatory journalism; democracy

\section{Referencia normalizada:}

Rubio Jordán, A.V. (2014): La aparición de InfoLibre y eldiario.es para la defensa de un periodismo más democrático y participativo. Historia y Comunicación Social. Vol. 19. Núm. Especial Enero. Págs. 491-500.

Sumario: 1. Estado de la cuestión. 2. Metodología. 3. Un modelo mixto de financiación. 4. Equipo fundacional. 4.1. La sociedad de amigos de InfoLibre. 5. Línea editorial e ideológica. 6. Conclusiones. 7. Referencias bibliográficas.

\section{Estado de la cuestión}

La capacidad de innovación en el periodismo a día de hoy es clave pues jamás la prensa escrita, y en particular la digital, estuvo tan asediada por la competencia como en la actualidad. El mayor riesgo al que se enfrenta un medio, sin tener en cuenta a la 
competencia, es precisamente la falta de innovación por parte de sus editores. Dicho riesgo nace de la ineptitud para analizar con precisión las evoluciones del mercado actual de la información, así como de la incorporación de las nuevas tecnologías. En palabras de González Urbaneja (2008: 11), "la crisis que asola actualmente al periodismo tradicional es fundamentalmente una crisis de credibilidad".

A este respecto, son varios los autores que coinciden con el ex presidente de la Asociación de la Prensa de Madrid al considerar que si bien las nuevas tecnologías han cambiado y multiplicado las formas de comunicación, no ha ocurrido de forma igual con el desarrollo de los contenidos periodísticos: "Se puede asegurar que el periodismo, por lo menos en España, no se ha planteado su actual razón de ser ante el desarrollo incontenible de las tecnologías de la comunicación y la información" (Diezhandino, 2007: 16).

La crisis económica que aún pervive en la actualidad ha provocado que el ejercicio de la profesión periodística se haya visto perjudicado debido, entre otras causas, al descenso en la inversión publicitaria. En los últimos años hemos presenciado el cierre de numerosas publicaciones en papel que no podían hacer frente a sus costes de producción y distribución mientras que su edición digital conseguía mantenerse a flote. Un ejemplo claro lo hemos visto en el diario Público, que cerró a principios de 2012 su edición impresa pero conservó la digital. La causa no fue otra que la dificultad por parte de la empresa editora del diario, Mediapubli, de encontrar inversores que apoyaran económicamente el proyecto.

Es indudable que la llegada de Internet provocó que los responsables de los medios de comunicación vieran en la Red un nuevo canal a través del cual distribuir sus informaciones. En este ámbito multimedia los modos en los que un ciudadano puede participar en una publicación han cambiado, produciéndose una transformación en las relaciones que se establecían de forma tradicional entre el emisor y el receptor. Este último se ha caracterizado por tener una actitud pasiva, limitándose a consumir noticias producidas por los medios sin la posibilidad de formar parte en ellos.

Gracias a las posibilidades que ofrecen las redes esta situación cambia y el receptor- pasivo se convierte en receptor- activo debido, sobre todo, a la interactividad que permiten las plataformas digitales. Este hecho "modifica la actitud psicológica que incide muy favorablemente en la credibilidad de los propios medios y en la seguridad del ciudadano con respecto a la información que recibe, ya que siente que en cierta medida tiene capacidad de incidir sobre ella" (Salvat y Paniagua, 2007: 234).

Ahora el usuario no solo es capaz de seleccionar de una manera fácil y rápida el canal en el cual desea informarse, sino que también puede participar y formar parte del medio en cuestión, puesto que no deja de ser testigo directo de infinidad de hechos que muchas publicaciones no logran abarcar.

Es lo que se ha denominado periodismo local o ciudadano, es decir, las aportaciones informativas realizadas por los usuarios en un medio digital por su propia voluntad. Este periodismo nace de la iniciativa del público a participar activamente de la labor 
informativa diaria efectuada por los medios. En opinión de algunos teóricos expertos en el tema, otra de las causas de la aparición del periodismo ciudadano es la quiebra interna del periodismo que, olvidando su función de responsabilidad social y garante de la democracia, se ha ido acercando cada vez más al poder político y económico.

\section{Metodología}

Una sociedad democrática se caracteriza por el derecho de sus ciudadanos a intervenir en la vida pública. De este modo, cualquier persona, hombre o mujer, se convierte en sujeto activo, este cambio "requiere que los medios de comunicación les reconozcan también como protagonistas activos del debate público, y no sólo como receptores pasivos de la acción política de unas minorías instaladas en los centros de poder" (Moreno y Simelio, 2008: 120).

Es precisamente en defensa de los valores democráticos y los ideales de justicia social cuando surgen algunos medios digitales, como son los que nos disponemos a estudiar aquí, que apuestan por un periodismo honesto e independiente pero no por ello sin dejar de un lado el rigor informativo. Un periodismo basado en atender las necesidades de los ciudadanos y no de los partidos políticos o intereses empresariales.

El objetivo de esta investigación es realizar una comparativa entre los digitales InfoLibre y eldiario.es. Para ello, se aplicará una metodología comparativa, puesto que ambos medios comparten una serie de similitudes, como son principalmente su línea editorial e ideológica, pero también mantienen notables diferencias que expondremos a continuación en los posteriores apartados. Las variables que se han tenido en cuenta para el estudio han sido su entramado empresarial, su fórmula mixta de financiación, la captación de socios y la participación de los lectores.

En el caso de eldiario.es se ha procedido a su seguimiento desde el momento en que aparece, esto es el 18 de septiembre de 2012. Este medio se caracteriza por realizar una firme apuesta por un periodismo riguroso e independiente a la vez que honesto. $\mathrm{Su}$ director es Ignacio Escolar, fundador y ex director de Público, de ahí que su plantilla esté formada principalmente por antiguos redactores de dicha publicación.

Para la evolución del segundo digital se han tomado datos desde el 7 de marzo de 2013, fecha en la que el diario ve la luz. Con lo cual, en la actualidad eldiario.es ya ha cumplido su primer año de vida mientras que InfoLibre acaba de alcanzar los siete meses de permanencia en la Red. Para el análisis comparativo hemos seleccionado los primeros seis meses en el que han convergido los dos diarios, es decir, desde marzo a septiembre de este año. Si bien somos conscientes de que los resultados obtenidos arrojarán una primera aproximación al tema de estudio quedando los mismos condicionados a un análisis posterior cuando se cumpla el primer aniversario de InfoLibre y, por ende, de ambos digitales. Teniendo en cuenta la fechas de aparición de los diarios, los datos se muestran analizando primero el medio de mayor antigüedad, 
es decir, el medio dirigido por Escolar, para, seguidamente, proceder al estudio de InfoLibre y la posterior comparativa entre ambos.

\section{Un modelo mixto de financiación}

Tanto InfoLibre como eldiario.es basan su modelo de negocio en una financiación mixta. Esta financiación se sustenta principalmente en los ingresos publicitarios. Como estos no suelen ser suficientes para mantener los ideales de independencia y honestidad que proclaman, necesitan otra vía de ingresos que, en el caso de ambas publicaciones, obtienen de las aportaciones que realizan sus socios. De este modo, los medios de comunicación necesitan inventarse a sí mismos, crear nuevos modelos de negocio "si quieren sobrevivir en medio de un panorama de libre competencia porque el valor de su marca no les asegura su supervivencia en el futuro cuando los actores informativos se han multiplicado del modo en el que lo han hecho" (Mahugo, 2010: 4).

Es por ello que, desde el momento de su lanzamiento, sendos diarios se lanzaron a la búsqueda de colaboradores mediante campañas publicitarias y ofertas para los primeros suscriptores con la finalidad de captar clientes. Socios, en definitiva, que compartan los mismos ideales que defiende el medio y, a la vez, se beneficien de las ventajas de la suscripción.

Los principales beneficios que ofrece ser socio tanto de InfoLibre como de eldiario.es se resumen en el adelanto de sus contenidos, es decir, el acceso a algunas de las informaciones del medio horas antes que el resto de los lectores. Además, los comentarios de los socios aparecen destacados en la web y los redactores tienen muy en cuenta las aportaciones realizadas. Otros servicios destacados son los descuentos y promociones en algunos servicios y actividades, principalmente, culturales.

InfoLibre se inspira en el modelo de negocio de Mediapart, su socio editorial, el cual lucha por la pervivencia de un periodismo libre e independiente, a la vez que apuesta por la investigación. Tal y como figura en sus principios fundacionales, el medio aspira a sostenerse con las aportaciones económicas que realicen sus socios, pero a diferencia de la publicación francesa, sus contenidos no serán todos de pago. El diario digital combina las informaciones exclusivas a las que únicamente tienen acceso los socios, con contenidos en abierto para todos los lectores.

Los suscriptores del diario que dirige Maraña tienen acceso a una selección de los mejores artículos publicados por Mediapart, que suelen ser informaciones en exclusiva, así como el acceso al Tuitómetro, una sección que recoge los mejores debates del día en la red social. En definitiva, las ventajas de ser socio en este diario supone principalmente el acceso a contenidos de calidad, recibir la portada con las informaciones que serán noticia al día siguiente a través del correo electrónico, formar parte de los contenidos del diario a través de los chat (todos los viernes se ofrece a sus 
lectores la posibilidad de realizar preguntas al director) y estar informado en todo momento acerca de las cuentas del medio.

Eldiario.es, si bien no tiene el servicio de enviar la portada del diario cada día a sus socios a través del correo electrónico, si ofrece a los mismos la posibilidad de participar en los encuentros fuera de la Red que la publicación se encarga de organizar. Estos encuentros se planifican de manera periódica con el objetivo de compartir ideas, críticas y aportaciones sobre la línea editorial que lleva a cabo el medio. Otra nota característica de este digital es que entre las ventajas de hacerse socio incluyen la gratitud, una gratitud personal y profesional que parte de los trabajadores de la empresa periodística hacia sus suscriptores por colaborar en un proyecto nuevo, por compartir los valores que defienden y por ayudar a que la información de actualidad llegue al ciudadano con rigor e independencia.

\section{Equipo findacional}

Eldiario.es es editado por la empresa Diario de Prensa Digital S.L., cuyo capital pertenece en más de un cincuenta por ciento a las personas que trabajan en el propio medio. Este hecho se justifica en la idea de que es una manera de que la publicación adquiera la libertad e independencia que propugna. El socio mayoritario de la empresa editora de eldiario.es es el director, Ignacio Escolar. Además son copropietarios algunos de los periodistas que componen su equipo redaccional, así como José Sanclemente, presidente de Diario de Prensa Digital S.L., y Joan Checa, director gerente. La publicación digital asegura en su web que no hay nadie mas detrás, ni intereses políticos, ni ninguna subvención. De igual modo, se indica que los becarios constituirán una parte mínima de la plantilla y serán objeto de remuneración, siendo la redacción cubierta en su mayoría por profesionales de la información.

Por su parte, el equipo que forma InfoLibre está compuesto por un grupo de periodistas encabezados por el ex director de Público Jesús Maraña. Este grupo de profesionales llegó a un acuerdo con el digital francés Mediapart, cuyo accionariado también se encuentra en manos de periodistas, y con el presidente de la editorial Edhasa, Daniel Fernández, para crear Ediciones Prensa Libre S.L., empresa editora del diario. Esta empresa ha decidido suscribir un pacto mediante el cual todas las decisiones editoriales son responsabilidad del equipo periodístico.

InfoLibre confía en la experiencia de su socio editorial para conocer qué funciona en los medios digitales de estas características y qué no. La publicación francesa se caracteriza por la búsqueda de grandes exclusivas, como por ejemplo, el "caso Bettencourt" en el que se vio envuelto el que era por entonces presidente de la nación Nicolás Sarkozy, al revelar el diario la financiación ilícita de la campaña presidencial por parte de la firma de cosméticos L'Óreal. Confiando en la experiencia de su socio, InfoLibre salió al mercado estrenándose con exclusivas como la imputación de Rodrigo Rato por el "caso Bankia" o el sonado "caso Bárcenas". 
Una de las principales diferencias que esta publicación mantiene con eldiario.es es el hecho de que cualquier ciudadano puede convertirse en accionista del medio. A los dos meses de su lanzamiento, InfoLibre informó de que cualquier persona física o jurídica podía ser accionista. Es decir, la estructura empresarial de este medio se crea pensando en cuatro núcleos de accionistas: los periodistas fundadores, el diario Mediapart, el presidente de la editorial Edhasa y los lectores. Para canalizar la participación de los lectores, se crea la Sociedad de Amigos de InfoLibre, impulsada por nombres relevantes del periodismo, el cine, la música y el arte, entre otros. Esta idea se basa en el ejemplo llevado a cabo por Mediapart.

\subsection{La sociedad de amigos de InfoLibre}

Mención aparte merece la Sociedad de Amigos de InfoLibre. Esta iniciativa ve la luz con el propósito de reunir, mediante la venta de participaciones que oscilan desde los 400 hasta los 12.000 euros, una cantidad total de 150.000 euros, que representarán un porcentaje aproximado del diez por ciento del capital social de Ediciones Prensa Libre. Además, se firma el "Manifiesto por un periodismo libre", con el objetivo de reivindicar la necesidad de un periodismo independiente y comprometido pero intransigente con los abusos de los poderosos. Este manifiesto recoge las firmas de músicos como Joan Manuel Serrat o Miguel Ríos, e intelectuales como Emilio Lledó o Federico Mayor Zaragoza.

Algunos de los impulsores de la Sociedad de Amigos de InfoLibre han colaborado en la realización de un vídeo de apoyo a este proyecto periodístico. Las imágenes, que han sido grabadas en la redacción del propio medio, finalizan con un llamamiento para que cualquier ciudadano que valore la importancia de una información libre se haga socio o accionista de este diario digital. Personajes relevantes del mundo de la cultura y el espectáculo protagonizan el vídeo, como Almudena Grandes, Toni Garrido, Verónica Sánchez, Pedro Almodóvar o Joaquín Sabina.

\section{Línea editorial e ideológica}

Los textos de opinión ayudan a definir con mayor claridad la línea editorial e ideológica de una publicación, por lo que la intervención del ciudadano en el medio se materializa a través de este género, el opinativo, consolidando la importancia de los diarios como "instrumentos fundamentales de debate en periodos políticamente conflictivos" (Escribano, 2006: 158).

El diario.es nace con el firme propósito de crear un periodismo riguroso e independiente pero también honesto. Aboga por la libertad, la justicia y la defensa de los derechos humanos; así como el progreso de la sociedad y el bienestar del conjunto de los ciudadanos. Sus principios editoriales se encuentran en la parte inferior de la página, en el enlace "¿Qué es el diario.es?”. El medio se describe como una publicación de información y análisis con el foco puesto en los problemas que afectan a 
los ciudadanos, antes que a partidos políticos o intereses empresariales. Este digital considera que existe una oferta informativa amplísima, pero que la misma es cada vez menos plural y mas asfixiante con el público lector.

Además de informar, el digital aboga porque el periodista ayude a sus lectores a comprender la realidad que le rodea, y que la labor del profesional de la información repercuta en el bienestar y el progreso de la sociedad. Esto se logra en mayor medida gracias a las redes sociales disponibles en Internet, potenciadoras del debate público entre los ciudadanos de un país.

En el caso de InfoLibre, sus contenidos vienen en gran medida condicionados de igual modo por la experiencia de su director, Jesús Maraña, quien también fue director de Público al igual que Ignacio Escolar. La publicación se define a sí misma como una propuesta informativa y cívica que nace en un momento en que la crisis económica amenaza, en su opinión, tanto a la democracia como al periodismo, los cuales están subordinados, siempre en palabras del propio medio, a los intereses del poder económico y financiero.

Sus principios editoriales van en la línea de eldiario.es, se trata de un medio que parte de la convicción de que es posible el ejercicio de un periodismo serio y profesional a la vez que libre e independiente. Un periodismo alejado de la influencia de los poderes políticos, económicos y empresariales. Para alcanzar este fin deben rechazar cualquier forma de financiación opaca y poco transparente. Además, un periodismo riguroso implica la diferenciación de los hechos de las opiniones, el respeto a las fuentes y la publicación de informaciones previamente contrastadas.

\section{Conclusiones}

Ante la grave crisis que vive el periodismo en nuestro país cada vez son mas los diarios que nacen solo en formato digital, es decir, para ser leídos exclusivamente a través de la web. Dos de esas publicaciones de reciente aparición, como son InfoLibre.es y eldiario.es, han hecho su incursión en el mercado de la prensa como abanderados de un periodismo de corte progresista, comprometidos con los valores que proclama nuestra democracia, la defensa de los derechos humanos y los valores cívicos de libertad, igualdad y solidaridad. En definitiva, ofrecen una forma de hacer periodismo muy en consonancia con lo que la sociedad actual reclama.

La principal apuesta de estos medios se centra en una fórmula mixta de financiación a través de dos vías: por un lado, los ingresos que obtienen de la venta de espacios publicitarios y, por otro, los ingresos procedentes del abono de cuotas por parte de los socios de la publicación.

Los digitales objeto de estudio son un claro ejemplo de un periodismo realizado por periodistas que reivindican su oficio y aspiran a comprar su libertad, en el sentido 
de que ambicionan ser los dueños de la redacción en la cual trabajan, de tal modo que no vean sometido su trabajo a intereses empresariales o partidistas.

Es indudable que Internet ha provocado que los responsables de los medios de comunicación tradicionales vieran un nuevo canal donde distribuir sus contenidos informativos. Hoy día el lector de diarios no se conforma con reaccionar ante la información servida o con debatirla con otros usuarios: quiere ser protagonista y convertirse, por tanto, en emisor de la información que se publica.

En el caso de los digitales analizados la principal relación con sus lectores se establece a través de los socios. Ambos medios coinciden en su modelo de financiación a través de una fórmula mixta, basada en los ingresos procedentes de la publicidad y en las aportaciones realizadas por sus socios. De igual modo, ambas publicaciones se caracterizan porque desde su aparición han protagonizado campañas destinadas a la captación de socios-colaboradores, transmitiendo el mensaje de que solo será posible la realización de un periodismo libre e independiente cuando no haya detrás ningún grupo empresarial o político.

En nuestro análisis comparativo hemos observado cómo la principal semejanza entre ambos son los principios editoriales que defienden. La creación de un periodismo libre e independiente, riguroso pero a la vez honesto, defensor de la libertad, igualdad, justicia, solidaridad y derechos humanos, en definitiva, valores intrínsecos en nuestro sistema democrático. La finalidad que persiguen es informar a los ciudadanos de todo lo que acontece en el día a día a la vez que realizan un trabajo que revierte en la sociedad.

Otra de las similitudes destacables es el hecho de que la figura del director está muy presente. Ignacio Escolar y Jesús Maraña han sido directores del desaparecido periódico en papel Público. De especial relevancia en esta publicación fue Escolar, puesto que además de ser el primer director fue también socio fundador. Este dato nos lleva a pensar que puede ser mas que una coincidencia el hecho de que los dos digitales de reciente aparición en nuestro país y defensores de un periodismo libre y sin ataduras, hayan sido directores de una publicación que mostraba sin tapujos su ideología de izquierdas.

Continuando la estela de las semejanzas, llama poderosamente la atención la transparencia en las cuentas. Ambos medios deciden publicar anualmente la procedencia de los ingresos que han obtenido, así como sus gastos, puesto que consideran un deber informar a los socios de forma periódica para que estos conozcan de primera mano qué se está haciendo con su dinero. Así, mientras eldiario.es anuncia que ha tenido solamente perdidas inferiores a 400 euros en su primer año de vida, InfoLibre tiene previsto llegar al punto de equilibrio en 2015. El diario que dirige Maraña ofrece también la posibilidad de ser accionista con participaciones a partir de los 400 euros, algo que hasta la fecha parece que no se plantea la publicación de Escolar.

En lo que respecta a su redacción, esta se compone sobre todo de periodistas que ya trabajaron para el desaparecido Público. El hecho de que InfoLibre haya puesto 
en marcha la Sociedad de Amigos de InfoLibre, así como el "Manifiesto por un periodismo libre", ha provocado que personajes destacados del mundo de la cultura, el espectáculo y el periodismo hayan apoyado los ideales que defiende el medio. También las ediciones entre ambos digitales es distinta por el momento, mientras eldiario.es ha abierto delegaciones en provincias como Cataluña, Andalucía, País Vasco, Galicia o Canarias, InfoLibre solo cuenta con la redacción de Madrid y no tiene por el momento previsto abrir ninguna otra.

Podemos concluir con el hecho de que la salida al mercado de estas publicaciones ha supuesto, desde el punto de vista empresarial, un acto de rebeldía, como posiblemente lo fue hace más de una década la aparición en nuestro país de la prensa gratuita, ya que implica una ruptura con el modelo tradicional de la economía de la empresa periodística basado exclusivamente en la venta de espacios publicitarios y se ha optado por una financiación en la que se hace participe de manera directa al lector, bien en forma de socio o bien como accionista, a través de sus distintas aportaciones económicas.

\section{Bibliografía}

ALONSO, J. y MARTÍNEZ, L. (2003). Manual de redacción ciberperiodística, medios interactivos, caracterización y contenidos. Barcelona: Ariel.

DIEZHANDINO NIETO, M. P. (coord.) (2007). Periodismo en la era de Internet. Claves para entender la situación actual de la información periodística en España. Colección Fundación Telefónica. Madrid: Ariel.

ESCRIBANO HERNÁNDEZ, A. (2006). Comentario de textos periodísticos: informativos, interpretativos y de opinión. Salamanca: Universidad de Salamanca.

MAHUGO, S. M. (2010). "Reinventar el periodismo: Medios necesariamente más participativos para una sociedad más democrática". En: Razón y Palabra, $\mathrm{n}^{\circ} 73$. Agosto- Octubre 2010.

MORENO SARDÁ, A. y SIMELIO SOLÁ, N. (2008). "Periodismo digital y democracia participativa". En: Análisi 36. p. 115-129.

SALVAT MARTINREY, G. y PANIAGUA SANTAMARÍA, P. (2007). “¿Es esto periodismo, ciudadano?". En: Estudios sobre el Mensaje Periodístico, vol. 13. p. 227-246.

URBANEJA, F. (2008). "La credibilidad de los medios". En: Cuadernos de Periodistas, $n^{\circ}$ 15. Madrid: APM. p. 9-22. 


\section{La autora}

Ana Virginia Rubio Jordán. Profesora adjunta en el Grado en Periodismo (UDIMA). Licenciada en Periodismo por la Universidad Complutense de Madrid y Doctora en Ciencias de la Información por la misma universidad. Máster en Periodismo de Agencia por la Universidad Rey Juan Carlos.

Ha desarrollado su labor profesional principalmente en la Agencia Efe, entre otros medios de comunicación, y ha impartido docencia en la Universidad Camilo José Cela. $\mathrm{Su}$ línea de investigación en particular es la prensa gratuita, así como la gestión de empresas informativas en general. 